\title{
Yarı kurak bölgelerde doğal ve plantasyon karaçam ormanlarının bazı toprak özellikleri ile organik karbon ve toplam azot depolama kapasitelerinin değerlendirilmesi
}

\author{
Ercan Işıık ${ }^{\mathrm{a}}$ (i), Ceyhun Göla," (i)
}

\begin{abstract}
Özet: Araştırma alanı, Çankırı İli, Eldivan İlçesi, Karataşbağı Deresi havzası içerisindedir. Araştırmanın amacı doğal ve plantasyon Anadolu Karaçam orman kuruluşlarında toprak özellikleri ile toprak organik karbon ve toplam azot depolama kapasitelerinin değişimini incelemektir. Çalışma için belirlenen örnek alanlarda $\left(400 \mathrm{~m}^{2}\right)$ meşcere parametreleri ile toprak ve ölü örtü özellikleri incelenmiştir. Çalışma alanlarında toprak çukurlarında genetik horizon esasına göre ve 50x50 m grid sisteminde üst toprak $(0-15 \mathrm{~cm})$ örneklemesi yapılmıştır. Toprakların fiziksel ve kimyasal analizlerine göre doğal ve plantasyon orman toprakları hafif bünyeli, orta kireçli ve hafif alkali özelliktedir. En düşük $\left(0,46 \mathrm{gr.cm}^{-3}\right)$ hacim ağırlığı doğal orman üst topraklarında ölçülmüştür. Üst topraklarda, depolanan organik karbon miktarları doğal ormanda 30,36 - 66,73 ton.ha ${ }^{-1}$, plantasyon ormanında 20,33 - 53,14 ton.ha ${ }^{-1}$, toplam azot miktarları ise sırasıyla 3,53 - 6,78 ve 2,05 - 5,29 ton.ha ${ }^{-1}$ dır. Doğal orman üst toprakların ortalama karbon miktarı 47,3 ton.ha $^{-1}$, plantasyon ormanlarının ise 32,2 ton.ha ${ }^{-1}$, ortalama toplam azot miktarları ise sırasıyla 4,9 ve 3,2 ton.ha ${ }^{-1}$ dır. Araştırmadan elde edilen sonuçlara göre plantasyon ile doğal orman toprakları benzer özellikler göstermiştir. Bu durum, ağaçlandırmanın başarılı olduğunu oraya koymuştur.

Anahtar kelimeler: Orman, Karbon, Azot, CBS, Çankırı
\end{abstract}

\section{Assessment of some soil properties and organic carbon and total nitrogen storage capacities of natural and plantation black pine forests in semi-arid regions}

\begin{abstract}
This research was carried out to investigate some soil properties and carbon and nitrogen storage status in natural and plantation black pine forest establishments in Çankırı province, Eldivan District, Eldivan Mountain. Sample areas $\left(400 \mathrm{~m}^{2}\right)$ were taken from natural and artificial forest areas to determine stand parameters, soil and litter properties. Based on genetic horizon in soil pits and topsoil $(0-15 \mathrm{~cm})$ sampling in $50 \times 50 \mathrm{~m}$ grid system was done in study areas. The physical and chemical properties of soils have been determined. The lowest $\left(0.46 \mathrm{~g} . \mathrm{cm}^{-3}\right)$ bulk density has been measured in natural forest topsoil. The organic carbon amounts of the upper soils in hectare are between $30.36-66.73$ tha $^{-1}$ in the natural forest and $20.33-53.14$ t.ha ${ }^{-1}$ in the plantation forest. Total nitrogen amounts are between 3.53-6.78 ve 2.05-5.29 ton.ha ${ }^{-1}$ respectively. The average carbon amount of

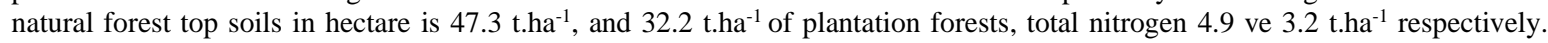
According to the results of this research, plantation and natural forest soils showed similar characteristics. This situation has shown that afforestation is successful.

Keywords: Forest, Carbon, Nitrogen, GIS, Çankırı
\end{abstract}

\section{Giriş}

Tüm dünyada sosyo-ekonomik değişimler, doğal kaynakları farklı oranda etkilemektedir. Bu etkinin en büyük sonucu ise Arazi Kullanım Türü ve Arazi Örtüsü (AKT/AÖ)'nün değişimidir. AKT/AÖ'de oluşan zamansal ve konumsal değişimlerin analizi, geleceğe dönük daha doğru kararların alınabilmesi için gereklidir (Lu vd., 2004; Göl, 2009; Seif ve Mokarram, 2012). Sanayi devrimi sonrası sera gazı salınımındaki artış sonucu küresel iklim değişikliği ortaya çıkmıştır (Lal, 2008; IPCC, 2014a). İklim değişikliğinin diğer bir nedeni ise yanlış ve aşırı arazi kullanımı sonucu karasal yutak alanların yok edilmesidir. Küresel ölçekte yıllık sera gazı emisyonunun \% 24'ü AKT/AÖ değişiminden kaynaklanmaktadır (IPCC, 2014b).

Dünya ülkeleri, küresel iklim değişikliği ile mücadele için sera gazı salınımlarının azaltılmasını ve karasal karbon yutak alanlarının nitelik ve nicelik olarak arttırılmasını amaçlamaktadır. Karasal ekosistemler içerisinde ormanlar büyük miktarlarda karbon depolamakta ve iklim değişikliği ile mücadelede kilit rol oynamaktadır (IPCC, 2007; Miles ve Kapos, 2008; Asan, 2012; Güner ve Makineci, 2017). Ormanlar, ulusal ve uluslararası anlaşmalarda en önemli karasal karbon yutak alanı olarak kabul edilmektedir.

\footnotetext{
$\triangle$ a Çankırı Karatekin Üniversitesi, Orman Fakültesi, Orman Mühendisliği Bölümü, 18200, Çankırı

@ * Corresponding author (İletişim yazarı): drceyhungol@ gmail.com

$\checkmark \quad$ Received (Geliş tarihi): 29.03.2021, Accepted (Kabul tarihi): 14.06.2021
}

Citation (Atıf): Işıı, E., Göl, C., 2021. Yarı kurak bölgelerde doğal ve plantasyon karaçam ormanlarının bazı toprak özellikleri ile organik karbon ve toplam azot depolama kapasitelerinin değerlendirilmesi. Turkish Journal of Forestry, 22(3): 202-210. DOI: $10.18182 /$ tjf. 905243 
Tüm dünyada ormanlık alanlar azalmaktadır (FAO, 2016). Türkiye'de ise ormanların korunması ve geliştirilmesi konusunda önemli çalışmalar ortaya konmaktadır. Türkiye'nin dünyadaki toplam $\mathrm{CO}_{2}$ emisyonları içerisindeki payının çok düşük olmasına rağmen (Karakaya ve Sofuoğlu, 2015) ortak olduğu sözleşmeler gereği azaltım, uyum ve yutak alanların korunması/geliştirilmesi konusunda birçok çalışma yürütülmektedir (Türkeş, 2008).

Türkiye'nin 1973 yılında 20,2 milyon hektar olan orman varlığı, 2019 yılında 22,7 milyon hektara çıkmıştır (OGM, 2021). Türkiye'deki orman alanı ve servetindeki bu artış, farklı kesimler tarafindan farklı nedenlere dayandırılmaktadır. Ormancılık örgütü bu artışın yapılan ağaçlandırma çalışmaları sonucu gerçekleştiğini söylerken farklı araştırmalar (Atmış, 2020) ise bu artışın ana nedeninin son yıllarda ülkede yaşanan sosyo-ekonomik yapıdaki değişimlerden (göç) kaynaklandığını iddia etmektedir.

$\mathrm{Bu}$ aşamada, ağaçlandırma çalışmaları ile ormanlık alanların artırılması büyük önem taşımaktadır. Türkiye'de ormanların tutmuş olduğu karbon miktarının ortaya konulması ve tutulan karbon miktarının zamansal ve konumsal değişimini belirlemeye yönelik birçok araştırma (Karatepe, 2004; Tolunay ve Çömez, 2008; Tolunay, 2015; Değirmenci ve Zengin, 2016; Seki vd., 2017) yapılmıştır. Orman alanlarının karbon depolama potansiyeli toprak altı ve üstü biyokütlenin hesaplanmasına bağlıdır.

Türkiye ormanlarının \% 19'unu Anadolu Karaçamı (Pinus nigra subsp. pallasina (Lamb.) Holmboe) ormanlar1 oluşturmaktadır (OGM, 2021). Karaçam, Türkiye'de 2150 metrelere kadar yetişebilmektedir (Kandemir ve Mataracı, 2018). Karaçam, stebe en çok sokulan ve kanaatkâr bir tür (Saatçioğlu, 1969) olması sebebiyle, ağaçlandırma çalışmalarında en çok kullanılan türlerden biridir. Özellikle İç Anadolu kurak bölge ağaçlandırmalarında tercih edilmektedir. Kurak alanlarda yapılacak ağaçlandırma çalışmalarının başarısında yetişme ortamının iyi analiz edilmesi, alana uygun bitki türlerinin seçimi, arazi hazırlığı ve bitkilendirme tekniklerinin doğru tespit edilerek uygulamaya aktarılması gereklidir (Güner ve Özkan, 2019). Dolayısıyla kurak alan karaçam ekosistem özelliklerin dikkatle incelenmesi gerekmektedir.

Bu çalıșma, yarı kurak bir bölgede doğal ve plantasyon Anadolu karaçamı ormanlarının bazı toprak özellikleri ile toprak organik karbon ve toplam azot depolama kapasiteleri arasındaki farklılıkları belirlemek amacıyla yürütülmüștür.

\section{Materyal ve yöntem}

\subsection{Araştırma alanının tanıtımı}

Araștırma alanı Çankırı İli, Eldivan İlçesi, Karataşbağı Deresi havzası içerisindedir. Konumu 40³4'41" - 40²0'38"

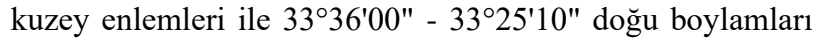
arasındadır. 1/25000 ölçekli topoğrafik haritada, Çankırı G31-d4 paftasında yer almaktadır (Şekil 1).



Şekil 1. Karataşbağı Deresi havzası yer bulduru haritası

Araştırmanın yürütüldüğü Karataşbağı Deresi havzasında, 1958 yılında Orman Umum Müdürlüğü, Çankırı Toprak Muhafaza ve Mera Islâhı Tatbikat Grup Müdürlüğü, Kara Dere Su Toplama Havzası Ön Etüt Raporu ve Tatbikat Raporu (OGM, 1958) ve 1960 yllında T.C. Nafia Vekaleti, Devlet Su İşleri Umum Müdürlüğü "Dumeli Kara Dere Yağış Alanı Islah Projesi" (DSİ, 1962) ile havza ıslah ve çıplak köklü karaçam fidanları $(2+0)$ ile ağaçlandırma çalışmalarına başlanmıştır.

Araştırma alanı, Karadeniz nemli iklimi ile Orta Anadolu kurak iklim kuşağı arasında olup, geçiş kuşağındadır. Karadeniz ikliminin etkisi altında kalan yüksek dağlık bölgelerde kuru ormanlar ve geniş mera alanları, İç Anadolu kurak iklimin etkin olduğu bölgelerde ise bozkır bitki örtüsü hakimdir (Göl, 2002; OGM, 2015a). Araştırma alanının da içinde bulunduğu Karataşbağı Deresi havzasında yıllık ortalama sicaklık $10,4^{\circ} \mathrm{C}$, yıllık ortalama yüksek sıcaklık $16,6{ }^{\circ} \mathrm{C}$, yıllık ortalama düşük sicaklık 4,8 ${ }^{\circ} \mathrm{C}$, en soğuk ay Ocak $\left(-0,5^{\circ} \mathrm{C}\right)$ ve en sicak ay Ağustos $(22,4$ $\left.{ }^{\circ} \mathrm{C}\right)$ tur (Göl ve Dengiz, 2007). Thornthwaite iklim sinıflandırma modeline göre bölge, DB'1db'3 rumuzu ile gösterilen "Kurak-yarı kurak, mezotermal, su fazlası yok 
veya pek az, denizel iklim etkisine yakın" iklim sınıfındadır (Göl, 2002; Göl ve Dengiz, 2007; Tuttu ve Akkemik, 2017).

Çankırı ili toprakları, Karadeniz Bölgesi ve Orta Anadolu Bölgesi olarak hemen hemen iki eşit parçaya bölünür (Gökmen, 2007). Çankırı ilinin kuzeyi III. Zamanda oluşmuş Oligosen-miyosen yaştaki jips serileri ile kaplıdır. Bu oluşum kalın ve kırmızı renkli bir taban konglomerası ile başlar, bunu açık renkli ve aralarında jips yatakları da bulunan kil ve marnlar izler (Blumenthal, 1948; Birgili vd., 1975). Araştırma alanı Eldivan ofiyolit kompleksi içerisindedir. Eldivan ofiyolit kompleksi Orta Anadolu'da gözlenen ofiyolitli melanj, yayılışında iç düzeni korunmuş okyanus kabuğu malzemesidir. Eldivan ofiyoliti; peridotit, pireksenolit gibi ultramafik kayaçlar, gabro, diyabaz, spilit gibi mafik kayaçlar ve radyolarit, kireçtaşı, çamurtaşı gibi pelajiksedimanter kayaçlardan meydana gelmektedir (Birgili vd., 1975). Bölge toprakları, orta ve hafif bünyeli, orta alkali, az tuzlu, orta ve yüksek kireçli ve organik madde miktarı düşüktür. Yüksek eğimli ve erozyona uğramış alanlarda topraklar sı̆̆, taşlı, geçirgenlikleri düşük ve yetersiz fizyolojik derinliğe sahiptir (Göl, 2002). Çankırı, Eldivan-Karataşbağı Deresi havzası toprakları, toprak taksonomisine göre (Soil Survey Staff, 1999) Lithic Xerorthent, Typic Xerorthent, Typic Calcicxerept, Typic Haploxerept, Lithic Calcicxerept ve Lithic Haploxerept sınıflarına dahil edilmiştir (Göl ve Dengiz, 2007).

Araştırma alanı, İran-Turan flora bölgesindedir. Bölgede yaygın ağaç ve çalı türleri; Pinus nigra J. F. Arnold subsp. pallasiana (Lamb.) Holmboe var. pallasiana (Anadolu Karaçamı), Quercus infectoria G.Olivier (Mazı Meşesi), Juniperus oxycedrus L. subsp. oxycedrus var. oxycedrus (Katran Ardıc1), Populus nigra L. (Kara Kavak), Elaeagnus angustifolia L. (İğde), Pyrus communis L. (Yabani Armut), Amygdalus communis L. (Badem), Robinia pseudoacacia L. (Yalancı Akasya), Crataegus monogyna Jacq. (Alıç), Berberis crataegina DC. (Karamuk), Paliurus spina - christi P. Mill. (Karaçalı), Ligustrum vulgare L. (Adi Kurtbağrı), Cotoneaster nummularia Fisch. \& C. A. Mey. (Dağ Muşmulası), Prunus spinosa L. (Çakal Eriği), Vitis sylvestris C.C. Gmel. (Yaban Asmas1), Rubus sp. (Böğürtlen), Jasminum fruticans L. (Sarı Çiçekli Yasemin), Rosa canina L. (Kuşburnu)'dır (Göl, 2002; Tuttu ve Akkemik, 2017).

Araştırmada, 2016 yılı sayısal meşcere ve jeoloji haritaları, amenajman planları, iklim verileri ile 1958-1960 yıllarında başlatılan ağaçlandırma ve erozyon kontrol projeleri (OGM, 1958; DSİ, 1962; OGM, 2015b) materyal kullanılmıştır. Ayrıca, araştırma alanından elde edilen bitki, toprak ve ölü örtü örnekleri materyal olarak değerlendirilmiştir. Karataşbağı Deresi havzasına ait sayısal veriler Coğrafi Bilgi Sistemi ortamına (ArcGIS 10.1 yazılımı ile) aktarılmış yükselti (Şekil 2), meşcere (Şekil 3) ve bakı (Şekil 4) haritaları oluşturulmuştur.

Havzanın Doğal Karaçam Ormanı (DKO) (542732 N, 4483610 E UTM-50) ve Plantasyon Karaçam Ormanı (PKO) (543114 N, 4483894 E UTM-50) alanlarından yetişme ortamı özellikleri (eğim, bakı, yükselti vb.) bakımından benzer özelliklere sahip örnek alanlar $\left(20 \times 20=400 \mathrm{~m}^{2}\right)$ tespit edilmiştir. Örnek alanlar içerisine giren tüm ağaçların göğüs yüksekliği çapları $\left(\mathrm{d}_{1,30}\right)(\mathrm{mm}$ hassasiyetinde, Haglöf Mantax mekanik çap ölçer ile), boyları (h) (m hassasiyetinde, Vertex Haglöf boy ölçer ile) ve yaşları (t) (Pressler artım burgusu ile ağaçtan kuzeygüney yönde olmak üzere alınan artım kalemlerinde yıllık halka sayımı ile) tespit edilmiştir. Meşcere üst boyu belirlenirken üst boydaki beş ağacın boy ortalaması alınmıştır (Kantarc1, 1980; Kantarcı, 2000).

Belirlenen iki örnek alanda toprak çukuru açılmış, genetik ve morfolojik incelemelere göre toprak tipleri belirlenmiştir (Kantarcı, 2000). Toprak çukurlarından genetik horizon esasına göre 9 adet doğal yapısı bozulmuş ve 7 adet bozulmamış toprak örneği alınmıştır. Ayrıca, üst topraklardan $(0-15 \mathrm{~cm}$ derinlik) $50 \times 50 \mathrm{~m}$ grid sistemine dayalı, toplam 60 adet doğal yapısı bozulmuş ve 60 adet bozulmamış (100 $\mathrm{cm}^{3}$ hacimli silindir ile) toprak örneği alınmıştır.

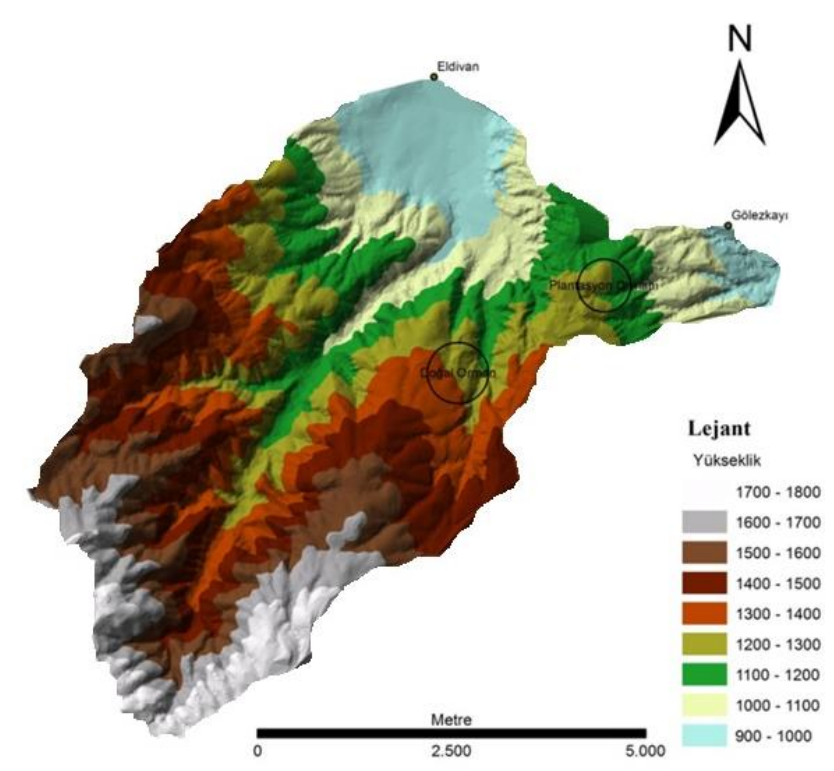

Şekil 2. Karataşbağı Deresi havzası yükseklik haritası ve çalışma alanları

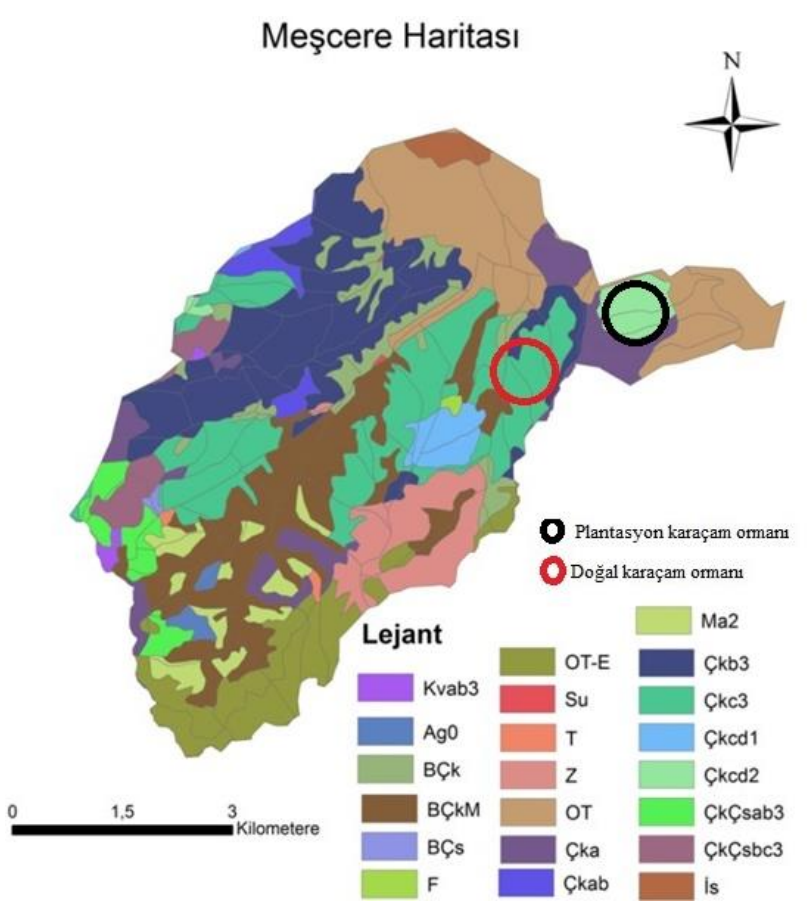

Şekil 3. Karataşbağı Deresi havzası meşcere haritası ve çalışma alanları 


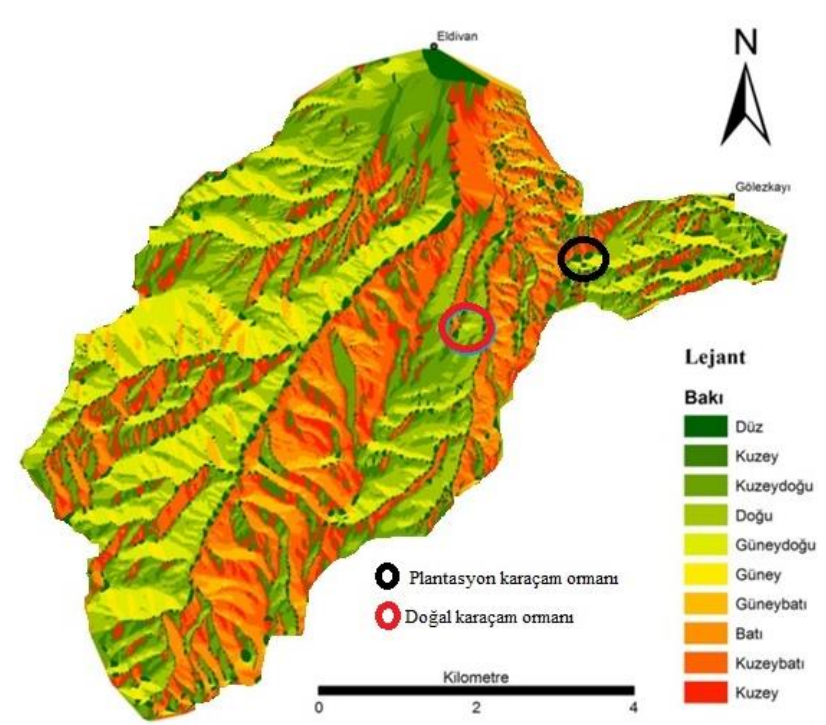

Şekil 4. Karataşbağı Deresi havzası bakı haritası ve çalışma alanları

Toprak örneklerinde; tane dağılımı (Bouyoucous hidrometre metodu) (Bouyoucous, 1951), toprak reaksiyonu (pH) 1/2,5 saf su çözeltisi (cam elektrotlu pH-metre) (U.S. Salinity Laboratory Staff, 1954), elektrik iletkenliği (EC) (cam elektrotlu pH-metre) (Rhoades, 1996), Kireç (CaCO3) (Scheibler kalsimetre yöntemi) (Richard ve Donald, 1996), toprak organik madde (Walkley-Black yaş yakma yöntemi) (Nelson ve Sommers, 1996), toplam azot (sömi-mikro Kjeldahl yöntemi) (Bremner, 1996) ve hacim ağırlı̆̆ (100 $\mathrm{cm}^{3}$ hacimli silindir yöntemi) (Blake ve Hartge, 1986) analizleri yapılmıştır. Hacim ağırlığı silindir örneklemesi genetik horizon esasına göre ve ayrıca sabit alınan üst toprak $(0-15 \mathrm{~cm})$ derinliğine göre yapılmıştır.

Toprak Organik Karbon (TOK) miktarı iskeletsiz (< 2,00 mm) mineral toprak içerisinde bulunan organik madde miktarı esas alınarak aşağıdaki formüle göre hesaplanmıştır (Mann, 1986; Nelson ve Sommers, 1996).

TOK $(\%)=0,58 *$ TOM $(\%)$

Üst topraklarda $(0-15 \mathrm{~cm})$ hektarda depolanan $\mathrm{TOK}_{\mathrm{h}}$ hesaplanmasında ise aşağıdaki formül kullanılmıştır (Tolunay ve Çömez, 2008; Pluske vd., 2013).

$\mathrm{TOK}_{\mathrm{h}}\left(\right.$ ton.ha $\left.{ }^{-1}\right)=$ TOK $(\%) * \mathrm{HA}\left(\mathrm{g} . \mathrm{cm}^{-3}\right) * \mathrm{~A}\left(\mathrm{~m}^{2}\right) *$ $\mathrm{TD}(\mathrm{m})$

$\mathrm{TOK}_{\mathrm{h}}$ hektarda toprak organik karbon miktarı (ton.ha ${ }^{-1}$ ), TOK $0-15 \mathrm{~cm}$ toprak derinliğindeki karbon içeriği (\%), HA bozulmamış silindir toprak örneğine göre belirlenmiş hacim ağırlığı $\left(\mathrm{g} \mathrm{cm}^{-3}\right)$, A toprak organik maddesinin kapladığ1 yüzey alanı $\left(10000 \mathrm{~m}^{2}\right)$, TD toprak derinliğini $(0,15 \mathrm{~m})$ ifade etmektedir.

Çalışmada belirlenen toprak özelliklerinin tanımlayıcı istatistikleri SPSS $^{\circledR} 20.0$ paket programı kullanılarak hesaplanmıştır. DKO ve PKO'ları yapısının bazı üst toprak özelliklerine etkilerini belirlemek amaciyla tek yönlü varyans (one-way ANOVA) analizi ve bağımsız iki örnek için t-testi (Independent sample t-test) yöntemi kullanılmıştır $(\mathrm{p}<0,05)\left(\mathrm{SPSS}^{\circledR} 20.0\right)$.

\section{Bulgular}

\subsection{Doğal ve plantasyon karaçam orman kuruluşlarının meşcere özellikleri}

Doğal Karaçam Ormanı (DKO) meşceresi üst ağaç katının (A1) hakim ağaç türü Anadolu karaçamıdır. Alt ağaç katında (A2) karışıma meşe katılmaktadır. Çalı katında meşe, alıç, patlangaç ve kuşburnu karışıma katılmaktadır. A1 katının kapalılı̆̆ $1 \%$ 80-100, A2 kat1 \% 60-80, çalı kat1 kapalılığ \% 10-30 olarak belirlenmiştir. İnsanların etkisi ile meşcere kapalılığının bozulduğu açıklıklarda gençlik gelmektedir.

DKO kuruluşu örnek alanında toplam 37 ağaç sayılmıştır. Tamamı Anadolu karaçam bireylerinden oluşan ağaçlarda en yüksek boy $32 \mathrm{~m}$, en yüksek göğüs çap1 $\left(\mathrm{d}_{1,30}\right)$ $40 \mathrm{~cm}$ ve en yüksek ağaç yaşı 115' dir. Aynı alanda en düşük ağaç boyu $12 \mathrm{~m}$, en küçük göğüs çap1 $\left(\mathrm{d}_{1,30}\right) 8 \mathrm{~cm}$ ve en düşük ağaç yaşı 51 ' dir.

Plantasyon Karaçam Ormanı (PKO) alanında tek tür (monokültür) ağaçlandırması yapılmış $2+0$ yaşında karaçam fidanları kullanılmıştır. PKO üst ağaç katında (A1) tam kapalılık (\% 80-100) sağlanmıştır. Ayrıca alt ağaç katında (A2) genç bireyler ve çalı katında gençlik geldiği belirlenmiştir. A2 katı kapalılık \% 70-80 ve çalı katı kapalılı̆̆ \% 10-20 dir. Çalı katında bol miktarda meşe, alıç, patlangaç, kuşburnu, ardıç ve dağ eriği türleri vardır.

PKO kuruluşu örnekleme alanında toplam 35 ağaç sayılmıştır. En yüksek ağaç boyu $21 \mathrm{~m}$, en yüksek göğüs çapı $\left(\mathrm{d}_{1,30}\right) 34 \mathrm{~cm}$, en yüksek ağaç yaşı 69 olarak ölçülmüştür. Alanda en düşük ağaç boyu $9 \mathrm{~m}$, en düşük gögüs çapı $\left(\mathrm{d}_{1,30}\right) 6 \mathrm{~cm}$ ve en düşük ağaç yaşı $28^{\prime}$ 'dir.

\subsection{Doğal ve plantasyon karaçam orman kuruluşlarının genel toprak özellikleri}

DKO örnek alanında açılan toprak çukurunda Ah, Ael, Bst, $\mathrm{BC}$ ve $\mathrm{Cv}$ horizonları, $\mathrm{PKO}$ ise $\mathrm{Ah}$, Ael, Bst ve $\mathrm{Cv}$ horizonları tanımlanmıştır. Her iki orman kuruluşunda toprak tipi “Kahverengi Orman Toprağı” dir.

Farklı orman kuruluşlarına göre toprak özellikleri Çizelge 1'de verilmiştir.

DKO örnekleme alanı 1283 m yükseltide, \% 20 eğimli, orta dağlık, erozyon sorunu olmayan bir alandadır. Toprakları kumlu killi balçık ve killi balçık, orta derin (80 $\mathrm{cm})$, granüller yapıda, hafif asit ve hafif alkali özelliktedir.

DKO toprak çukurunda $0-20 \mathrm{~cm}$ derinlikte bol ince ve seyrek kalın kökler, $20-40 \mathrm{~cm}$ derinlikte bol orta ve kalın kökler, $40+\mathrm{cm}$ derinlikte seyrek kalın kökler yayılış göstermektedir. Bitki kök gelişimini engelleyecek sorun yoktur.

PKO örnekleme alanı $1232 \mathrm{~m}$ yükseltide, orta dağlık, dalgalı arazi yapısındadır. Alan \% 36 eğimde, topraklar sı ̆̆ ve orta derin, bol taşlı, erozyon sorunu yoktur. PKO toprakları kumlu killi balçık, orta derin, granüller ve masif yapıda, hafif asit, hafif ve orta alkali özelliktedir.

PKO toprak çukurunda $0-38 \mathrm{~cm}$ derinlikte bol ince kök, $38-70 \mathrm{~cm}$ derinliklerde bol orta kalın ve 70-113 cm derinlikte seyrek kalın kökler belirlenmiştir. Kök gelişimi orta düzeydedir.

Her iki örnek alanda toprak üzerinde $0-5 \mathrm{~cm}$ ve $0-7 \mathrm{~cm}$ kalınlıklarda değişmek üzere çürüntülü mull tipi humus bulunmaktadir. 
DKO alanında açılan toprak çukurunda, horizonlara göre hacim ağırlı̆̆ değerleri $0,75-1,13$ gr. $\mathrm{cm}^{-3}$, plantasyon ormanında 0,9-1,10 gr. $\mathrm{cm}^{-3}$ arasında değişmektedir (Çizelge 1). Toprak derinliği arttıkça hacim ağırlığı da artmaktadır.

DKO toprak reaksiyonları üst horizonlarda hafif asit $(\mathrm{pH}$ 6,9), alt horizonlarda hafif alkali $(\mathrm{pH} \mathrm{7,5)}$ dir. PKO toprak reaksiyonları benzer özellik göstermiş üst horizonlarda hafif asit (pH 6,8), alt horizonlarda hafif alkali $(\mathrm{pH} 7,6)$ dir.

DKO üst toprakları az kireçli $(\% 1,46)$, alt toprakları orta kireçli $(\% 5,75)$ dir. PKO üst toprakları orta $(\% 8,65)$, alt toprakları çok kireçli $(\% 14,48)$ dir.

Her iki orman kuruluşu topraklarında tuzluluk sorunu yoktur. Topraklar az ve orta tuzlu sinıfindadır.

DKO toprak çukuru üst topraklarında Organik Madde (OM) zengin (\% 7,85), Toprak Organik Karbon (TOK) $(\%$ 4,51) ve Toplam Azot (TA) (\% 0,3924) miktarları yüksektir (Çizelge 1). PKO toprak çukuru üst toprakları OM miktarı orta zengin $(\% 3,18)$ özelliktedir. PKO topraklarında OM miktarları \% 1,11-3,18, TOK miktarları \% 0,99-1,84, TA miktarları ise \% 0,0236-0,1079 arasında değişmektedir (Çizelge 1).

Üst topraklarda ölü örtü ayrışma ürünleri toprakların OM, TOK ve TA değerlerinin yüksek ölçülmesinde neden olmuştur. Örnek alanlarda açılan toprak çukuru DKO topraklarının OM ve hektarda toprak organik karbon $\left(\mathrm{TOK}_{\mathrm{h}}\right)$ depolama kapasitesi üst topraklarda daha yüksek ölçülmüştür. DKO örnek alanı toprak çukuru topraklarında depolanan $\mathrm{TOK}_{\mathrm{h}}$ miktarı 23,2-102,5 ton.ha ${ }^{-1}$, PKO topraklarında ise 19,7-51,5 ton. $\mathrm{ha}^{-1}$ arasında değişim göstermiştir. Toprak derinliği ile $\mathrm{TOK}_{\mathrm{h}}$ depolama kapasitesi azalmıştır.

Her iki örnek alanda açılan toprak çukuru toprakları içerisinde en yüksek (102,5 ton.ha $\left.{ }^{-1}\right)$ TOK $_{\mathrm{h}}$ depolama kapasitesi DKO Ah horizonu topraklarında ölçülmüştür.

DKO toprak çukuru horizon topraklarında depolanan toplam azot miktarı $\left(\mathrm{TA}_{\mathrm{h}}\right)$ 1,2-5,1 ton.ha ${ }^{-1}$, PKO topraklarında ise 1,7-1,9 ton.ha $^{-1}$ arasında değişim göstermiştir. Her iki orman topraklarında derinlik arttıkça, depolanan toplam azot miktarı azalış göstermiştir. DKO $\mathrm{A}_{\mathrm{h}}$ horizon topraklarında en yüksek 5.1 ton.ha ${ }^{-1}$ toplam azot depolama kapasitesi belirlenmiştir. PKO topraklarında depolanan toplam azot miktarı tüm genetik horizonlarda yaklaşık benzer özellik göstermiştir.

\subsection{Doğal ve plantasyon karaçam ormanı üst toprak özellikleri arasındaki farklar}

Bağımsız iki örnek t-testi (Independent sample t-test) ile DKO ve PKO'larındaki üst toprak özelliklerine ilişkin bazı ortalamalar karşılaştırılmıştır. Buna göre; hacim ağırlığı değişkeni bakımından \% 95 güvenle iki orman kuruluşu üst toprakları arasında istatistiksel olarak anlamlı bir farklılık yoktur (F: 0,001; df: 58) (Çizelge 2).

Kum (F: 1,599; df: 58 ), kil (F: 0,299; df: 58), OM (F: 0,010; df: 58), TOK (F: 0,011; df: 58), TOK $(\mathrm{F}: 0,012$; df: 58), TA (F: 1,410; df: 58), TA $(1,039$; df:58), kireç (F: 1,778; df: 58), toprak reaksiyonu $(\mathrm{pH})(\mathrm{F}: 9,163$; df: 58) toprak özellikleri bakımından iki orman kuruluşu üst toprakları arasında \% 95 güven düzeyinde istatiksel olarak anlamlı $(\mathrm{p}<0,05)$ bir farklılık olduğu belirlenmiştir (Çizelge 2).

Araştırma kapsamında incelenen DKO ve PKO üst toprak $(0-15 \mathrm{~cm})$ özellikleri Çizelge 3'te verilmiştir. DKO üst topraklarında kum miktarı \% 48-67, PKO topraklarında ise \% 57-70 arasında değişim göstermiştir. Hacim ağırlığı değerleri DKO topraklarında 0,46-1,18 gr.cm ${ }^{-3}$, PKO üst topraklarında 0,59-1,12 gr. $\mathrm{cm}^{-3}$ arasındadır (Çizelge 3).

Kireç miktarları DKO üst topraklarında çok az kireçli ve orta kireçli $(\% 0,29-13,84)$ sinıflarındadır. PKO üst topraklarında ise \% 0,29-14,57 arasında ve doğal orman toprakları ile benzer kireç sınıfındadır.

Toprak reaksiyonları bakımından DKO üst toprakları hafif asit (pH 6,34) ve hafif alkali $(\mathrm{pH} \mathrm{7,33)} \mathrm{özelliktedir.}$ PKO üst toprakları ise hafif alkali $(\mathrm{pH} 7,07)$ ve orta alkali (pH 7,71) özellik göstermiştir (Çizelge 3).

OM, TOK ve TA bakımından DKO ve PKO üst toprakları farklı özellikler göstermiştir. DKO üst topraklarında OM \% 4,03-8,02, TOK \% 2,34-4,65 ve TA \% 0,21-0,41 ile zengin ve çok zengin özellik göstermiştir. PKO üst toprakları ise OM \% 2,75-7,83, TOK \% 1,60-4,54 ve TA \% 0,14-0,98 depolama özelliği ile orta ve zengin özellik göstermiştir (Çizelge 3).

Çizelge 1. Araştırma alanı topraklarının bazı fiziksel ve kimyasal analiz sonuçları

\begin{tabular}{|c|c|c|c|c|c|c|c|c|c|c|c|c|c|c|c|c|}
\hline \multirow{2}{*}{$\begin{array}{c}\text { Orman } \\
\text { Kuruluşu }\end{array}$} & \multirow{2}{*}{ Horizon } & \multirow{2}{*}{$\begin{array}{c}\text { Derinlik } \\
\text { (cm) }\end{array}$} & \multicolumn{3}{|c|}{ Tane Dağılımı (\%) } & \multirow{2}{*}{$\begin{array}{c}\text { Toprak } \\
\text { Türü }\end{array}$} & \multirow{2}{*}{$\begin{array}{c}\text { HA } \\
\left({\left.\mathrm{gr} . \mathrm{cm}^{-3}\right)}^{-3}\right.\end{array}$} & \multirow{2}{*}{$\mathrm{pH}$} & \multirow{2}{*}{$\begin{array}{l}\text { Tuz } \\
(\%)\end{array}$} & \multirow{2}{*}{$\begin{array}{c}\mathrm{EC} \\
(\mathrm{dS} / \mathrm{m})\end{array}$} & \multirow{2}{*}{$\begin{array}{c}\text { Kireç } \\
(\%)\end{array}$} & \multirow{2}{*}{$\begin{array}{l}\mathrm{OM} \\
(\%)\end{array}$} & \multirow{2}{*}{$\begin{array}{c}\text { TOK } \\
(\%)\end{array}$} & \multirow{2}{*}{$\begin{array}{c}\mathrm{TOK}_{\mathrm{h}} \\
\left(\text { ton.ha }^{-1}\right)\end{array}$} & \multirow{2}{*}{$\begin{array}{l}\text { TA } \\
(\%)\end{array}$} & \multirow{2}{*}{$\begin{array}{c}\mathrm{TA}_{\mathrm{h}} \\
(\text { ton.ha } \\
\end{array}$} \\
\hline & & & Kil & Toz & Kum & & & & & & & & & & & \\
\hline \multirow{5}{*}{$\begin{array}{l}\stackrel{0}{a} \\
\frac{a}{a}\end{array}$} & $\mathrm{Ah}$ & $0-5$ & 27 & 17 & 56 & KuKB & 0,75 & 6,9 & 0,12 & 0,261 & 1,46 & 7,85 & 4,51 & 102,5 & 0,392 & 5,1 \\
\hline & Ael & $5-21$ & 35 & 23 & 42 & $\mathrm{~KB}$ & 1,03 & 6,7 & 0,12 & 0,188 & 3,83 & 3,56 & 2,06 & 63,8 & 0,177 & 3,2 \\
\hline & Bst & $21-35$ & 35 & 25 & 40 & $\mathrm{~KB}$ & 1,04 & 7,3 & 0,13 & 0,148 & 5,73 & 2,10 & 1,22 & 38,1 & 0,105 & 1,9 \\
\hline & $\mathrm{BC}$ & $35-55$ & 27 & 25 & 48 & KuKB & 1,13 & 7,5 & 0,08 & 0,117 & 5,19 & 1,18 & 0,69 & 23,2 & 0,059 & 1,2 \\
\hline & $\mathrm{Cv}$ & $55+$ & 29 & 21 & 50 & KuKB & - & 7,4 & 0,09 & 0,198 & 5,75 & 0,32 & 0,09 & - & - & - \\
\hline \multirow{4}{*}{$\frac{0}{a}$} & $\mathrm{Ah}$ & $0-7$ & 22 & 21 & 57 & KuKB & 0,93 & 6,8 & 0,09 & 0,196 & 2,96 & 3,18 & 1,84 & 51,5 & 0,107 & 1,7 \\
\hline & Ael & $7-15$ & 20 & 17 & 63 & KuKB & 1,09 & 7,1 & 0,11 & 0,151 & 8,65 & 2,16 & 1,25 & 41,2 & 0,101 & 1,9 \\
\hline & Bst & $15-25$ & 22 & 23 & 55 & KuKB & 1,10 & 7,6 & 0,13 & 0,152 & 9,38 & 1,03 & 0,58 & 19,7 & 0,085 & 1,6 \\
\hline & $\mathrm{Cv}$ & $25+$ & 25 & 23 & 52 & KuKB & - & 7,6 & 0,07 & 0,123 & 14,48 & 0,13 & 0,08 & - & - & - \\
\hline
\end{tabular}

Not: KuKB-kumlu killi balçık, KB-killi balçık, HA- hacim ağırlı̆̆ı, pH-1/2,5 Saf Su, EC- elektriksel iletkenlik, OM- organik madde, TOK-toprak organik karbon, TAtoplam azot, $\mathrm{TOK}_{\mathrm{h}}$ - hektarda depolanan toprak organik karbon, $\mathrm{TA}_{\mathrm{h}}$ - hektarda depolanan toplam azot 
Çizelge 2. Doğal ve plantasyon karaçam ormanı üst toprak $(0-15 \mathrm{~cm})$ özelliklerine ilişkin istatistiksel analiz sonuçları $(\mathrm{n}=30)$

\begin{tabular}{|c|c|c|c|c|c|c|}
\hline Değişkenler & Birim & $\begin{array}{c}\text { Orman } \\
\text { kuruluşu }\end{array}$ & $\bar{X}$ & SD & $\mathrm{t}$ & $\mathrm{F}$ \\
\hline \multirow{2}{*}{ Kum } & \multirow{2}{*}{$(\%)$} & DKO & 55 & 4,42 & \multirow{2}{*}{$-7,181$} & \multirow{2}{*}{$0,000^{* *}$} \\
\hline & & $\mathrm{PKO}$ & 62 & 3,21 & & \\
\hline \multirow{2}{*}{ Kil } & \multirow{2}{*}{$(\%)$} & $\mathrm{DKO}$ & 21 & 2,45 & \multirow{2}{*}{4,416} & \multirow{2}{*}{$0,000 * *$} \\
\hline & & PKO & 18 & 1,89 & & \\
\hline \multirow{2}{*}{$\mathrm{OM}$} & \multirow{2}{*}{$(\%)$} & $\mathrm{DKO}$ & 6,29 & 0,84 & \multirow{2}{*}{9,173} & \multirow{2}{*}{$0,000 * *$} \\
\hline & & $\mathrm{PKO}$ & 4,14 & 0,97 & & \\
\hline \multirow{2}{*}{ TOK } & \multirow{2}{*}{$(\%)$} & DKO & 3,65 & 0,48 & \multirow{2}{*}{9,198} & \multirow{2}{*}{$0,000 * *$} \\
\hline & & $\mathrm{PKO}$ & 2,40 & 0,56 & & \\
\hline \multirow{2}{*}{$\mathrm{TOK}_{\mathrm{h}}$} & \multirow{2}{*}{ (ton.ha ${ }^{-1}$ ) } & $\mathrm{DKO}$ & 47,32 & 7,53 & \multirow{2}{*}{8,915} & \multirow{2}{*}{$0,001 * *$} \\
\hline & & PKO & 32,24 & 7,35 & & \\
\hline \multirow{2}{*}{ TA } & \multirow{2}{*}{$(\%)$} & DKO & 0,31 & 0,04 & \multirow{2}{*}{2,724} & \multirow{2}{*}{$0,009 * *$} \\
\hline & & $\mathrm{PKO}$ & 0,23 & 0,14 & & \\
\hline \multirow{2}{*}{$\mathrm{TA}_{\mathrm{h}}$} & \multirow{2}{*}{ (ton.ha ${ }^{-1}$ ) } & DKO & 4,96 & 0,74 & \multirow{2}{*}{1,857} & \multirow{2}{*}{$0,003 * *$} \\
\hline & & $\mathrm{PKO}$ & 3,26 & 0,77 & & \\
\hline \multirow{2}{*}{ HA } & \multirow{2}{*}{$\left(\mathrm{gr} \mathrm{cm}^{-3}\right)$} & DKO & 0,86 & 0,15 & \multirow{2}{*}{$-1,156$} & \multirow{2}{*}{$0,252^{\mathrm{ns}}$} \\
\hline & & $\mathrm{PKO}$ & 0,90 & 0,13 & & \\
\hline \multirow{2}{*}{ Kireç } & \multirow{2}{*}{$(\%)$} & DKO & 2,45 & 3,71 & \multirow{2}{*}{$-3,896$} & \\
\hline & & $\mathrm{PKO}$ & 6,34 & 3,99 & & 0,000 \\
\hline $\mathrm{nH}$ & & $\mathrm{DKO}$ & 6,68 & 0,72 & & $0000 * *$ \\
\hline pH & & $\mathrm{PKO}$ & 7,31 & 0,13 & $-4,032$ & 0,000 \\
\hline
\end{tabular}

DKO ormanı üst topraklarında hektarda toprak organik karbon $\left(\mathrm{TOK}_{\mathrm{h}}\right)$ depolama kapasitesi 30,36 66,73 ton.ha ${ }^{-1}$, PKO üst topraklarında ise 20,33 - 53,14 ton.ha ${ }^{-1}$ dir. Ortalama $\mathrm{TOK}_{\mathrm{h}}$ depolama kapasitelerine bakıldığında DKO üst topraklarında 47,3 ton.ha ${ }^{-1}$, PKO üst topraklarında ise 32,2 ton.ha ${ }^{-1}$ olduğu belirlenmiştir (Çizelge 3).

PKO alanında üst toprak özellikleri, DKO üst topaklarına göre $\mathrm{OM}, \mathrm{TOK}_{\mathrm{h}}$ ve $\mathrm{TA}_{\mathrm{h}}$ depolama kapasiteleri bakımından daha çok değişkenlik göstermiştir $(\% \mathrm{Cv})$ (Çizelge 3). DKO üst toprakları daha yüksek asidik, daha yüksek OM, TOK ve TA içermektedir.

Hektarda depolanan toplam azot $\left(\mathrm{TA}_{\mathrm{h}}\right)$ miktarı bakımından DKO üst toprakları 3,53-6,78 ton.ha ${ }^{-1}$ arasında değişim göstermekte, ortalama ise 4,9 ton.ha ${ }^{-1}$ dır. PKO üst topraklarında depolanan $\mathrm{TA}_{\mathrm{h}}$ miktarı 2,05-5,29 ton.ha ${ }^{-1}$, ortalama ise 3,2 ton.ha ${ }^{-1}$ dir.

\section{Tartışma ve sonuç}

Araştırmanın yürütüldüğü Karataşbağı Deresi havzasında 1958-1960 yıllarında başlayan ve daha sonra devam eden ağaçlandırma ve erozyon kontrol çalışmaları ile havzanın \% 27'si ağaçlandırılmış ve çalışmalarda başarıya ulaşılmıştır (Göl ve Dengiz, 2007). Göl ve Dengiz, (2007)'de yaptıkları çalışmada Karataşbağı Deresi havzasının arazi kullanım türü ve arazi örtüsü dağılımında, bozuk karaçam ve bozuk baltalık alanlarında azalma (-\%
5,7), ormandan dönüştürülen tarım arazilerinde azalma (-\% 15,8), buna karşılık karaçam ormanlarında artış (+\% 21,3) olduğunu belirlemişlerdir. Erozyon tehlikesi olan yüksek eğimli yerlerde ağaçlandırma çalışmalarına devam edilmelidir. Ağaçlandırmalarda tek tür yerine karışık orman kuruluşuna gidilmelidir.

Anadolu Karaçamı ülkemizde geniş bir yayılış alanına sahiptir. Orta Anadolu kurak iklim bölgelerinde ise yüksek rakımlı bölgelerde verimli ormanlar oluşturabilmektedir Anadolu Karaçamı sıcaklığa, donlara ve kuraklığa dayanıklı bir türdür (Saatçioğlu, 1969; Kayacık, 1980). Bu özelliği ile yayılış alanları dışında kurak mıntıka ağaçlandırmalarında tercih edilmektedir. Araştırma alanı, Eldivan Dağı yamaçlarında 1200-1300 m yükseltilerdedir. Bölgenin iklimi yarı kurak-yarı nemlidir. Yürütülen ağaçlandırma çalışmaları oldukça başarılı sonuçlar vermiş, plantasyon sahalarında tam kapalı ormanlar oluşmuştur. Bölgenin iklim, toprak ve diğer ekolojik özellikleri bakımından Anadolu Karaçamı türü için ağaçlandırmaya uygun olduğu anlaşılmaktadır. Yazıcı ve Babalık (2011)'de yürüttükleri çalışmada Anadolu Karaçamı fidanlarının kuraklığa dayanıklı olduğunu tespit etmişlerdir.

Araştırma alanı toprakları orta derin, orta taşlı, kum ve kil miktarı yüksektir. Doğal Karaçam Ormanı (DKO) toprakları homojen özellik gösterirken, Plantasyon Karaçam Ormanı (PKO) toprakları değişken özelliktedir. Bu durum ağaçlandırma çalışmaları için yapılan toprak işleme faaliyetlerinin etkisi olarak düşünülmektedir. Kalıpsız (1963)'de doğal karaçam meşcerlerinde yürüttüğü çalışmasında toprak derinliğinin ağaç büyümesinde önemli bir faktör olduğunu belirtmiştir. Erkan (1998) çalışmasında karaçamın derin topraklı ve düz alan ağaçlandırmalarında daha başarılı olduğunu belirtmiştir.

Araştırma alanı topraklarında $\mathrm{Ah}$ horizonundan $\mathrm{CV}$ horizonuna doğru kil ve kireç oranı artmaktadır. Toprak reaksiyonu, üst topraklardan alt topraklara gidildikçe alkalileşmektedir. Benzer araştırmalarda Cangir (1982) ve Atalay (2006) karstlaşmış ana kayalardan oluşmuş olan topraklarda kil ve kireç miktarının derinlik arttıkça arttığını bildirilmiştir. Polat vd. (2014)'de üst topraklarda kireç miktarının düşük olmasını yıkanmaya bağlamışlardır.

DKO üst topraklarında genel olarak OM, TOK, $\mathrm{TOK}_{\mathrm{h}}$, TA ve $\mathrm{TA}_{h}$ değerleri yüksek, hacim ağırlığı düşüktür. Polat vd. (2014) ve Göl vd. (2010) çalışmalarında saf karaçam meşcereleri altındaki topraklarda ince toprak miktarı, toplam kireç, organik karbon, tüm azot miktarlarını yüksek bulmuşlardır. Güner vd. (2011), Anadolu Karaçamı ağaçlandırmalarının gelişimi ile yetişme ortamı özellikleri arasındaki ilişkileri inceledikleri çalışmalarında; organik karbon, toplam azot, hacim ağırlığı arasında önemli ilişkiler bulunmuştur. 
Çizelge 3. Doğal ve plantasyon karaçam orman üst toprak $(0-15 \mathrm{~cm})$ özelliklerine ilişkin tanımlayıcı istatistikler, $(\mathrm{n}=$ 30)

\begin{tabular}{|c|c|c|c|c|c|c|c|c|c|}
\hline $\begin{array}{l}\text { Orman } \\
\text { Kuruluşu }\end{array}$ & Değişken & & Min. & Maks. & $\overline{\mathrm{X}}$ & SD & Çarpıklık & Basıklık & $\mathrm{Cv}$ \\
\hline \multirow{10}{*}{ DKO } & Kum & $(\%)$ & 48 & 67 & 55 & 4,4 & 0,71 & 0,61 & 7,98 \\
\hline & Kil & $(\%)$ & 16 & 27 & 21 & 2,4 & 0,28 & 1,03 & 11,50 \\
\hline & $\mathrm{OM}$ & $(\%)$ & 4,03 & 8,02 & 6,3 & 0,8 & $-0,50$ & 0,60 & 13,34 \\
\hline & TOK & $(\%)$ & 2,34 & 4,65 & 3,6 & 0,4 & $-0,50$ & 0,60 & 13,32 \\
\hline & $\mathrm{TOK}_{\mathrm{h}}$ & (ton.ha ${ }^{-1}$ ) & 30,36 & 66,73 & $.7,3$ & 7,5 & $-0,49$ & 0,58 & 15,87 \\
\hline & TA & $(\%)$ & 0,20 & 0,41 & 0,3 & 0,1 & $-0,65$ & 0,49 & 15,20 \\
\hline & $\mathrm{TA}_{\mathrm{h}}$ & (ton.ha ${ }^{-1}$ ) & 3,53 & 6,78 & 4,9 & 0,7 & $-0,68$ & 0,35 & 14,28 \\
\hline & HA & $\left(\mathrm{gr} \mathrm{cm}^{-3}\right)$ & 0,46 & 1,18 & 0,8 & 0,2 & $-0,64$ & 1,00 & 18,22 \\
\hline & Kireç & $(\%)$ & 0,29 & 13,84 & 2,4 & 3,7 & 2,27 & 4,25 & 51,24 \\
\hline & $\mathrm{pH}$ & & 3,34 & 7,33 & 6,6 & 0,7 & $-3,58$ & 16,57 & 10,77 \\
\hline \multirow{10}{*}{ PKO } & Kum & $(\%)$ & 57 & 70 & 62 & 3,2 & 0,13 & $-0,38$ & 5,13 \\
\hline & Kil & $(\%)$ & 16 & 22 & 18 & 1,9 & 0,16 & $-0,82$ & 10,06 \\
\hline & $\mathrm{OM}$ & $(\%)$ & 2,75 & 7,83 & 4,1 & 0,9 & 1,93 & 6,38 & 23,55 \\
\hline & TOK & $(\%)$ & 1,60 & 4,54 & 2,4 & 0,6 & 1,94 & 6,46 & 23,48 \\
\hline & $\mathrm{TOK}_{\mathrm{h}}$ & (ton.ha ${ }^{-1}$ ) & 20,33 & 53,14 & $i 2,2$ & 7,3 & 1,87 & 5,49 & 22,67 \\
\hline & TA & $(\%)$ & 0,14 & 0,98 & 0,2 & 0,1 & 4,63 & 23,34 & 33,90 \\
\hline & $\mathrm{TA}_{\mathrm{h}}$ & (ton.ha ${ }^{-1}$ ) & 2,05 & 5,29 & 3,2 & 0,7 & 5,72 & 17,23 & 21,87 \\
\hline & $\mathrm{HA}$ & $\left(\mathrm{gr} \mathrm{cm}^{-3}\right)$ & 0,59 & 1,12 & 0,9 & 0,1 & $-0,55$ & $-0,14$ & 15,36 \\
\hline & Kireç & $(\%)$ & 0,29 & 14,57 & 6,3 & 3,9 & 0,37 & $-0,65$ & 62,99 \\
\hline & $\mathrm{pH}$ & & 7,07 & 7,71 & 7,3 & 0,1 & 0,65 & 1,86 & 1,79 \\
\hline
\end{tabular}

$\overline{\mathrm{X}}$ - aritmetik ortalama, SD- standart sapma, Cv- varyasyon katsay1s1

DKO topraklarında ölü örtünün ayrışma hızına bağlı olarak hektarda karbon depolama kapasitesi $A_{h}$ ve $A_{e l}$ genetik horizonlarında daha yüksektir. Sarıyıldız vd. (2008) çalışmasında türlerin ölü örtü ayrışma oranlarının içerdikleri lignin miktarı ve yetişme ortamı şartlarına göre değiştiğini, Karaçam ormanı ölü örtüsünün soğuk ve kurak ekosistemlerde daha hızlı ayrıştığını ortaya koymuşlardır. Raich ve Schlesinger (1992) ölü örtü ayrışmasının yıllık 68 $\mathrm{Pg} \mathrm{C} \mathrm{y}_{1} 1^{-1} \quad(\mathrm{Pg}=1015 \mathrm{~g})$ olarak belirtmiştir. Karasal ekosistemlerde karbon bütçesinin hesaplanmasında, ormanlardaki ölü örtü ayrışması yüzde 70 rol oynamakta ve bu nedenle de önemli bir yer tutmaktadır (Sarıyıldız vd, 2008). Çakır vd. (2019) Çankır1-Eldivan yöresinde yaptıkları çalışmada karaçam meşcerelerinde ayrışma hızını $\%$ 25-30, Sarıyıldız vd. (2008) Ankara'da \%26 bulmuşlardır. Karaçam ibrelerinin ayrışma süresince karbon ve azot yoğunluğunun meşcere gelişim çağlarına göre istatistiksel olarak farklılık gösterdiğini belirtmişleridir.

Araştırma alanı DKO üst toprakları $\mathrm{TOK}_{\mathrm{h}}$ miktarları 47,3 ton.ha ${ }^{-1}$, PKO üst topraklarında 32,2 ton.ha ${ }^{-1}$ olarak belirlenmiştir. Tolunay ve Çömez (2008) çalışmasında Türkiye genelinde 219 örnek alan çalışmasından elde ettikleri sonuçlara göre karaçam ormanlarında topraktaki organik karbon miktarlarının ortalama 71,6 Mg.ha- ${ }^{-1}(6,7-$ 296,5), ağaçlandırma alanlarında ise 65,1 Mg.ha' ${ }^{-1}$ (9,3$174,6)$ olduğunu ortaya koymuşlardır. Bu durum araştırma alanı üst topraklarının ülke geneli karaçam orman topraklarına göre düşük $\mathrm{TOK}_{\mathrm{h}}$ depolama kapasitesine sahip olduğunu ortaya koymaktadır. Karatepe (2004) Gölcük'teki karaçam meşcerelerinde farklı yetişme ortamı şartlarında toprakların organik karbon ve toplam azot depolama kapasitelerinin değiştiğini belirtmiştir. Bunda ise ana kaya ve özellikle topoğrafik yapının etkili olduğunu ortaya koymuştur.

Araştırma alanı, erozyon, sel ve taşkın sorununu çözmek amacıyla yürütülen başarılı bir toprak muhafaza ağaçlandırma sahasıdır. PKO topraklarının, fiziksel ve kimyasal özellikler bakımından DKO toprak özelliklerine yaklaştığı anlaşılmaktadır. Başarılı bir ağaçlandırma çalışması sonucunda toprakta yüksek miktarda OM, TOK, ve TA birikimi sağlanmıştır. Yürütülen benzer çalışmalarda da (Yüksek, 2012; Yazıcı ve Turan, 2016) ağaçlandırma sonrasi toprakların organik karbon ve toplam azot miktarının arttığını belirlenmişlerdir.

Küresel iklim değişikliği ile mücadele ormanlık alanların ve toprakta depolanan organik karbon miktarının arttırılması büyük önem taşımaktadır (IPPC 2007; 2014b).

$\mathrm{Bu}$ araştırma ile ülkemizin kurak bölgelerinde havza ıslahı ve sera gazı yutak ormanlarını artırma amaçlı ağaçlandırma çalışmalarının önemini bir kez daha ortaya konulmuştur. Araştırma plantasyon karaçam ormanları üst topraklarının OM, TOK ve TA depolama kapasitesi bakımından en az doğal ormanlar kadar iyi olduğunu ortaya koymuştur.

\section{Açılklama}

Bu araştırma, TÜBİTAK 2209-A 1919B011502133 No'lu "Üniversite Öğrencileri Yurt İçi Araştırma Projeleri” kapsamında desteklenmiştir. Arazi ve laboratuvar çalışmalarındaki desteklerinden dolayı Araş. Gör. Dr. Semih EDIŞ̧'e ve istatistiksel analiz desteklerinden dolayı Doç. Dr. İlker Ercanlı'ya teşekkür ederiz.

\section{Kaynaklar}

Asan, Ü., 2012. Türkiye ormanlarındaki yıllık karbon stok değişimi trendinin irdelenmesi ve 2023 yılındaki durumun kestirilmesi. Kahramanmaraş Sütçü İmam Üniversitesi, Doğa Bilimleri Dergisi, 1: 109-120.

Atalay, İ., 2006. Toprak oluşumu, sınıflandırılması ve coğrafyası. Çevre ve Orman Bakanlığı, AGM yayınları, III. baskı, Meta Basım, Ankara.

Atmış, E., 2020. Türkiye orman varlığıyla ilgili değişimler ve nedenleri, (İçinde: TOD, 2020. Türkiye Ormancilar Derneği'nin 95. kuruluş yıldönümünde: orman varlığımız ve ormancılık üretim faaliyetleri, (Edt: K. Ok), ISBN: 978-97593478-8-8, 82 sayfa, Ankara.

Birgili, Ş., Ünalan, G., Yoldaş, R., 1975. Çankırı-Çorum havzası'nın jeolojisi ve petrol olanakları, MTA Genel Müdürlügü Raporu, Rap., No: 5621, Ankara.

Blake, G.R., Hartge K.H., 1986. Bulk density and particle densty. in: Methods of Soil Analysis Part1. Physical And Minerological Methods. pp: 363-381. Asa. And SSSA. Agronomy Monograph No: 9 Madison, Wiscosin USA. 
Blumenthal, M., 1948. Bolu civarı ile aşağı Kızılırmak mecrası arasındaki Kuzey Anadolu silsilesi’nin jeolojisi, MTA Genel Müdürlüğü Raporu, Rap No. 2026, Ankara.

Bouyoucous, G.J.A., 1951. Recalibration of the hydrometer for making mechanical analysis of soil. Agronomy Journal (Journal of American Society of Agronom) 43: 434-438.

Bremner, J.M., 1996 Inorganic form of nitrogen in: C.A. Black Et All. Methods of Soil Analysis Part 2. Agronomy 9: 1179-1237 Am.Soc. of Agron., Inc. Madison, Wiscosin USA.

Cangir, C., 1982. Kireçli materyaller üzerinde oluşmuş kahverengi, kırmızıms1-kahverengi, terra rossa, rendzina ve grumusol toprakların morfoloji ve genesisleri, Ankara Üniversitesi, Ziraat Fakültesi, Toprak Bölümü, Ankara.

Çakır, M., Akbudak, S., Sargıncı, M., 2019. Çankırı bölgesi karaçam (Pinus nigra Arnold.) mesccerelerinde ölü örtü ayrışması ile mikroeklembacaklılar ve mikrobiyal aktivitenin zamansal değişimi ve toprağa verilen besin maddeleri. TÜBITTAK Proje Raporu, Proje No: 215O572, Ankara.

Değirmenci, A.S., Zengin, H., 2016. Ormanlardaki karbon birikiminin konumsal ve zamansal değişiminin incelenmesi: Daday planlama birimi örneği. Artvin Çoruh Üniversitesi Orman Fakültesi Dergisi, 17(2): 177-187.

DSİ, 1962. Çankırı, Dümeli, Karadere havza ıslah projesi, Devlet Su İşleri Genel Müdürlüğü, Ankara

Erkan, N., 1998. Elazığ yöresindeki sedir ve karaçam ağaçlandırmalarında büyüme analizleri, Orman Bakanlığı, Güneydoğu Anadolu Ormancılık Araștırma Müdürlüğü, Yayın No: 4, Elazığ

FAO, 2016. Global Forest Resources Assessment 2015. U.N. Food and Agricultural Organization of The United Nations FAO) Yayını. Roma-İtalya.

Gökmen, B., 2007. Çankırı ili coğrafyası. Ankara Üniversitesi, Sosyal Bilimler Enstitüsü, Coğrafya (Türkiye Coğrafyası) Anabilim Dalı, Doktora Tezi, Ankara.

Göl, C., 2002. Çankırı Eldivan yöresinde arazi kullanım türleri ile bazı toprak özellikleri arasındaki ilişkiler. Ankara Üniversitesi, Fen Bilimleri Enstitüsü, Doktora Tezi, Ankara.

Göl, C., Dengiz, O., 2007. Çankırı-Eldivan Karataşbağı deresi havzası arazi kullanım-arazi örtüsündeki değişim ve toprak özellikleri. OMÜ. Ziraat Fakültesi Dergisi, 22 (1): 86-97.

Göl, C., 2009. The effects of land use change on soil properties and organic carbon at Dağdamı river catchment in Turkey. Journal of Environmental Biology, 30(5): 825-830.

Göl, C., Sezgin, M., Dölarslan, M., 2010. Evaluation of soil properties and flora under afforestation and natural forest in semi arid climate of central Anatolia. Journal of Environmental Biology, 31(1-2): 21-31.

Güner, D., Özkan, K., 2019. Türkiye'deki karaçam ağaçlandırma alanlarında besin stoklarının belirlenmesi. Ormancilık Araştırma Dergisi, 6(2): 192-207.

Güner, Ş.T., Çömez, A., Karataş, R., Çelik, N. ve Özkan, K., 2011. Eskişehir ve Afyonkarahisar illerindeki Anadolu Karaçamı (Pinus nigra Arnold. subsp. pallasina (Lamb.) Holmboe) ağaçlandırmalarının gelişimi ile bazı yetişme ortamı özellikleri arasındaki ilişkiler, ÇOB, Orman, Toprak ve Ekoloji Araştırmaları Enstitüsü Müdürlüğü, Teknik Bülten No: 1, Eskişehir.

Güner, Ş.T., Makineci, E., 2017. Determination of annual organic carbon sequestration in soil and forest floor of Scots pine forests on The Türkmen Mountain (Eskişehir, Kütahya). İstanbul University, Journal of the Faculty of Forestry, 67(2): $109-115$.

IPCC, 2007. Climate Change 2007: The physical science basis. (Ed: Solomon, S., Qin, D., Manning, M., Marquis, M., Averyt, K. B., Tignor, M.M.B., Miller, H.L.M. and Chen, Z.) Frequently Asked Questions and Selected Technical Summary Boxes. Canada
IPCC, 2014a. Climate Change 2014: Mitigation of Climate Change. (Ed: Edenhofer, O. R., Pichs-Madruga, R., Sokona Y., Minx, J.C., Farahani, E., Kadner, S., Seyboth, K., Adler, A., Baum, I., Brunner, S., Eickemeier, P., Kriemann, B., Savolainen, J., Schlömer, S., von Stechow, C. and Zwickel, T.). Cambridge University Press, Cambridge, UK and New York, NY, USA, pp. 1435.

IPCC, 2014b. Climate Change 2014: Synthesis Report. Contribution of Working Groups I, II and III to the Fifth Assessment Report of the Intergovernmental Panel on Climate Change [Core Writing Team, R.K. Pachauri and L.A. Meyer (eds.)]. IPCC, Geneva, Switzerland, pp: 151.

Kalıpsız, A., 1963. Türkiye'de karaçam meşcerelerinin tabii bünyesi ve verim kudretleri üzerine araştırmalar, OGM Yayın No: 349/8, Ankara.

Kandemir, A., Mataracı, T., 2018. Resimli Türkiye Florası, Cilt 2. (Edt: Güner, A., Kandemir, A., Menemen, Y., Yıldırım, H., Aslan, S., Ekşi, G., Güner, I., Çimen, A. Ö). ss: 324-354. A NG Vakfı Nezahat Gökyiğit Botanik Bahçesi Yayınları. İstanbul.

Kantarc1, M.D., 1980. Belgrad ormanı toprak tipleri ve orman yetişme ortamı birimlerinin haritalanması üzerine araştırmalar. İ.Ü. Orman Fak. İ.Ü. Yayın No: 2636, Fak. No: 275, İstanbul.

Kantarc1, M.D., 2000. Toprak İlmi Ders Kitab1 (2. bask1), İ.Ü. Yayın No: 4261, Orman Fakültesi Yayın No: 462, (XII+420), Çantay Basımevi, ISBN: 975-505-588 -7, İstanbul.

Karakaya, E., Sofuoğlu, E., 2015. İklim değişikliği müzakerelerine bir bakış: 2015 Paris iklim zirvesi. International Symposium on Eurasia Energy Issues. 28-30 Mayıs, İzmir.

Karatepe, Y., 2004. Gölcük (Isparta)’ te karaçam (Pinus nigra Arn. supsp. pallasiana (Lamb.) Holmboe) meşcerelerinin topraklarındaki toplam azot ve organik karbon ile ölü örtülerindeki toplam azot ve organik madde miktarlarının araştırılması. Süleyman Demirel Üniversitesi, Orman Fakültesi Dergisi, A(2): 1-16.

Kayacık, H., 1980. Orman ve Park Ağaçlarının Özel Sistematiği: Gymnospermea. İ.Ü. Orman Fakültesi yayın, No: 281, İstanbul.

Lal, R., 2008. Carbon sequestration. Philesophical Transactions, 363: $815-830$.

Lu, D., Mausel, P., Brondı'zio, E., Moran, E., 2004. Change detection techniques. International Journal of Remote Sensing, 25: 2365-2407.

Mann, L., 1986. Changes in soil carbon storage after cultivation. Soil Science. 142, p.279-288.

Miles, L., Kapos, V., 2008. Reducing greenhouse gas emissions from deforestation and forest degradation: Global land-use implications. Science, 320: 1454-1455.

Nelson, D.W., Sommers, L.E., 1996. Total carbon, organic carbon and organic matter. In: Sparks, D.L. (Ed.), Methods of Soil Analysis. Part 3. Chemical Methods, SSSA Book Ser. 5. 3. Soil Science Society of America, Madison, USA, pp. 961-1010.

OGM, 1958. Karadere su toplama havzası ön etüt raporu ve tatbikat raporu. Ankara Orman Başmüdürlüğü, Toprak Muhafaza ve Mera Islâhı Tatbikat Grup Müdürlüğü, Ankara.

OGM, 2015a. Türkiye Orman Varlığ 1 2015. T.C. Orman ve $\mathrm{Su}$ İşleri Bakanlığı, Orman Genel Müdürlüğü, 32s., Ankara.

OGM, 2015b. 1996-2015 Amenajman Planı, Ankara Orman Bölge Müdürlüğü, Çankırı Orman İşletme Müdürlüğü, Merkez İşletme Şefliği Amenajman Planı, Çankırı.

OGM, 2021. Ormancilık İstatistikleri 2019. https://web.ogm.gov.tr/ekutuphane/Sayfalar/ Istatistikler.aspx? RootFolder $=\% 2$ Fekutuphane $\% 2$ FIstatistikler\%2FOrmanc\%C4 $\% \quad \mathrm{~B} 11 \% \mathrm{C} 4 \% \mathrm{~B} 1 \mathrm{k} \% 20 \% \mathrm{C} 4 \%$ B0statistikleri\&FolderCTID= 0x012000301D182F8CB9FC 49963274E712A2DC00\& $\mathrm{View}=\{4 \mathrm{~B} 3 \mathrm{~B} 693 \mathrm{~B}-\mathrm{B} 532-4 \mathrm{C} 7 \mathrm{~F}-\mathrm{A} 2 \mathrm{D} 0-732 \mathrm{~F} 715 \mathrm{C} 8 \mathrm{CC}\}$, Erişim: 29.03.2021. 
Polat, S., Polat, O., Kantarcı, M.D., Tüfekçi, S., Aksay, Y., 2014. Mersin-Kadıncık havzası'ndaki sedir (Cedrus libani A. Rich.) ve Karaçam (Pinus nigra Arnold.) ağaçlandırmalarının boy gelişimi ile bazı yetişme ortamı özellikleri arasındaki ilişkiler. Ormancılık Araştırma Dergisi, 1A(1): 22-37.

Pluske, W., Murphy, D., Sheppard, J., 2013. Note on Total organic carbon; http://soilquality.org.au/factsheets/ organic-carbon, Erişim: 30.05.2021.

Raich, J.M., Schlesinger, W.H., 1992. The global carbondioxide flux in soil respiration and its relationship to vegetation and climate. Tellus, 44B: 81-99.

Rhoades, J.D., 1996. Methods of Soil Analysis. Part 3. Chemical Methods. Soil Science of America and American Society of Agronomy. SSSA Book Series No.5. Madison-USA. pp: 417437

Richard, H.L., Donald, L.S., 1996. Methods of Soil Analysis. Part 3. Chemical Methods. Soil Science of America and American Society of Agronomy. SSSA Book Series No. 5. MadisonUSA. pp: 437-475.

Sarıyıldız, T., Varan, S., Duman, A., 2008. Ölü örtü ayrışma oranları üzerinde kimyasal bileşenlerin ve yetişme ortamı özelliklerinin etkisi: Artvin ve Ankara yöresine ait örnek bir çalışma. Kastamonu Üni., Orman Fakültesi Dergisi, 8(2): 109119.

Saatçioğlu, F., 1969. Silvikültür I, silvikültürün biyolojik esasları ve prensipleri. İstanbul Üniversitesi Orman Fakültesi Yayınları, 323s, İstanbul.

Seif, A., Mokarram, M., 2012. Change detection of gil playa in the northeast of Fars province. Iran Am. J. Sci. Res. 86: 122-130.

Seki, M., Sakıcı, O.E., Büyükterzi, M., Sağlam, F., 2017. Taşköprü Orman İşletme Müdürlüğü ormanlarında karbon stoğunun zamansal değişimi. Uluslararası Taşköprü Pompeiopolis Bilim Kültür Sanat Araştırmaları Sempozyumu, 10-12 Nisan, Taşköprü, Kastamonu, s. 1564-1577.
Soil Survey Staff, 1999. Soil Taxonomy. A Basic of Soil Classification for Making and Interpreting Soil Survey. USDA Handbook No: 436, Washington D.C.

Tolunay, D., 2015. Türkiye'de ormansızlaşma ile kaybedilen karbon miktarları. 6. Ulusal Hava Kirliliği ve Kontrolü Sempozyumu,7-9 Ekim 2015, İzmir.

Tolunay, D., Çömez, A., 2008. Orman topraklarında karbon depolanması ve Türkiye'deki durum. Küresel İklim Değişimi ve Su Sorunlarının Çözümünde Ormanlar. 13-14 Aralık 2007, İstanbul, ss: 97-108.

Tuttu, G., Akkemik, Ü., 2017. Çankırı-Korubașı tepe ve civarındaki jipsli alanların florası. Ot Sistematik Botanik Dergisi, 24(1):45-88.

Türkeş, M., 2008. İklim değişikliğiyle savaşım, Kyoto protokolü ve Türkiye. Mülkiye, XXXII (259): 103-133.

U.S. Salinity Laboratory Staff, 1954. Diagnosis improvement of saline and alkali soils. Agri. Handbook, No: 60, USDA.

Yazıcı, N., Babalık, A.A., 2011. Anadolu karaçamı (Pinus nigra Arn. subsp. pallasiana (Lamb.) Holmboe.) fidanları için uygun sulama aralığının belirlenmesi. Bartın Orman Fakültesi Dergisi, 13(19): 100-106.

Yazıc1, N., Turan, A., 2016. Effect of forestry afforestation on some soil properties: A case study from Turkey. Fresenius Environmental Bulletin, 25(7): 2509-2513.

Yüksek, T,. 2012. The restoration effects of black locust (Robinia pseudoacacia L.) plantation on surface soil properties and carbon sequestration on lower hillslopes in the semi-humid region of Coruh Drainage Basin in Turkey. Catena, 90: 18-25. 